\title{
Compensation for nuclear damage: a comparison among the international regime, Japan and China
}

Citation for published version (APA):

Liu, J., \& Faure, M. (2016). Compensation for nuclear damage: a comparison among the international regime, Japan and China. International Environmental Agreements-Politics Law and Economics, 16(2), 165-187. https://doi.org/10.1007/s10784-014-9252-7

Document status and date:

Published: 01/04/2016

DOI:

10.1007/s10784-014-9252-7

Document Version:

Publisher's PDF, also known as Version of record

Document license:

Taverne

Please check the document version of this publication:

- A submitted manuscript is the version of the article upon submission and before peer-review. There can be important differences between the submitted version and the official published version of record.

People interested in the research are advised to contact the author for the final version of the publication, or visit the DOI to the publisher's website.

- The final author version and the galley proof are versions of the publication after peer review.

- The final published version features the final layout of the paper including the volume, issue and page numbers.

Link to publication

\footnotetext{
General rights rights.

- You may freely distribute the URL identifying the publication in the public portal. please follow below link for the End User Agreement:

www.umlib.nl/taverne-license

Take down policy

If you believe that this document breaches copyright please contact us at:

repository@maastrichtuniversity.nl

providing details and we will investigate your claim.
}

Copyright and moral rights for the publications made accessible in the public portal are retained by the authors and/or other copyright owners and it is a condition of accessing publications that users recognise and abide by the legal requirements associated with these

- Users may download and print one copy of any publication from the public portal for the purpose of private study or research.

- You may not further distribute the material or use it for any profit-making activity or commercial gain

If the publication is distributed under the terms of Article $25 \mathrm{fa}$ of the Dutch Copyright Act, indicated by the "Taverne" license above, 


\title{
Compensation for nuclear damage: a comparison among the international regime, Japan and China
}

\author{
Jing Liu • Michael Faure
}

Accepted: 11 April 2014/Published online: 30 April 2014

(C) Springer Science+Business Media Dordrecht 2014

\begin{abstract}
Following the Fukushima disaster in Japan in 2011, how the compensation system for nuclear damage should be improved has obtained broad attention. The compensation system, including liability rules, insurance and government involvement, does not only concern to what extent the victims can be sufficiently compensated, but is also relevant to create incentives for the nuclear industry to enhance safety. International compensation regimes for nuclear damage started to emerge since 1960s, but still fail to engage some (potentially) big "nuclear power" ones. The Japanese and Chinese systems are such ones which received less attention until recently. This paper will, on the one hand, engage in a positive study by giving a comparison between the international regime, the Japanese and the Chinese system; on the other hand, provide a normative analysis by using economic criteria to examine the efficiency of the systems and formulate suggestions for reform.
\end{abstract}

Keywords Nuclear liability · Insurance - Financial cap · Limit on liability · Disaster
Abbreviations
CSC The Convention on Supplementary Compensation for Nuclear Damage
GPCL The General Principles of Civil Law of the People's Republic of China
IAEA The International Atomic Energy Agency
INES International Nuclear Event Scale

\footnotetext{
J. Liu $(\bowtie)$

Wuhan University, Wuhan, China

e-mail: jing.liu@maastrichtuniversity.nl

M. Faure

Comparative and International Environmental Law, Maastricht University, Maastricht, The Netherlands e-mail: Michael.faure@maastrichtuniversity.nl
}

M. Faure

Comparative Private Law and Economics, Erasmus University Rotterdam, Rotterdam, The Netherlands 
NEA The Nuclear Energy Agency

OECD Organisation for Economic Co-operation and Development

PQA The Product Quality Act of the People's Republic of China

SDRs Special Drawing Rights

TEPCO The Tokyo Electric Power Company

\section{Introduction}

Following the Great East Earthquake in Japan in 2011, the subsequent Fukushima accident has shocked the world and triggered fierce debates on the future of nuclear energy in many countries. Among many topics under debate, the question how the compensation system for nuclear damage, including liability rules should be improved has obtained much attention. The compensation system does not only answer the question to what extent the victims of a nuclear accident can be sufficiently compensated, but is also relevant to create incentives for the nuclear industry to move toward a safer world. The liability rules and related regime, such as nuclear liability insurance and government involvement, together influence the extent to which the external costs of nuclear energy can be internalized and thus the precautionary measures the nuclear industry takes. This paper will use economics analysis to examine the compensation system for nuclear damage, including liability rules, nuclear insurance, government support and some other related instruments.

A nuclear accident may have serious transboundary effects. The international community has tried to establish a common framework for the compensation of nuclear damage since the 1960s. ${ }^{1}$ Though some general principles have been established, ${ }^{2}$ the international conventions failed to establish a common compensation framework in the international community (Duncan 2008). Many countries, including some big "nuclear power" ones still stay out of the international regimes, such as the US and Japan.

The literature has focused strongly on the US nuclear liability system under the PriceAnderson Act. However, less attention has been paid to other equally important ones, like the Japanese system, at least until the recent Fukushima accident. This regime has, so we will argue, some equally interesting features. The Japanese system shares some common characteristics with the international regime. However, there are significant differences as well. For example, the nuclear operators in Japan face uncapped liability. Moreover, the practice after the Fukushima accident shows not only on paper, but also in practice, how nuclear damage is compensated. Some new developments took place since then, such as the ex post establishment of a risk-sharing pool among the nuclear operators.

China is, like Japan, also not a member of the international regimes. Although China so far only had a moderate capacity of nuclear energy, it may become a global player since many new nuclear power plants are planned to be constructed in the following decades. ${ }^{3}$ However, the development of its nuclear compensation system is not in-line with its

${ }^{1}$ Two international regimes have been established until now under the auspices of the Nuclear Energy Agency (NEA) of the Organisation for Economic Cooperation and Development (OECD) and the International Atomic Energy Agency (IAEA) (the Paris Convention regime and Vienna Convention regimes).

${ }^{2}$ More specifically, strict liability, channelled liability to the nuclear operators; limited liability with mandatory insurance and exclusive jurisdiction. For details, see infra Section 2.

${ }^{3}$ The "Medium- and Long-term Nuclear Power Development Plan (2005-2020)," shows China is planning to increase its nuclear capacity to $40 \mathrm{GWe}$ by 2020 . The nuclear industry produced only $7 \mathrm{Gwe}$, which 
nuclear ambitions. Although two replies of the State Council on nuclear liability issues ${ }^{4}$ adopted similar principles as the international regime, many issues are still left unclear. Moreover, the replies are only normative documents, but not a statute according to the hierarchy of the Chinese legal system. A comprehensive nuclear energy act is still on its way.

This paper will, on the one hand, engage in a positive study by giving a comparison between the international regime, the Japanese and the Chinese system ${ }^{5}$; on the other hand, we will make a normative analysis by using economic criteria to examine the efficiency of the systems and formulate suggestions for reform. ${ }^{6}$

This paper will be structured as follows: after a brief introduction concerning the compensation system for nuclear damage (1), the paper will analyze the three systems, respectively: the international regime (2), the Japanese system (3) and the Chinese system (4). Not only liability rules are discussed, some other compensation instruments such as insurance, public funds and risk-sharing agreements are also presented. Following the analysis of the individual systems, a short comparison will be made between the three systems (5). We will further examine the systems from the law and economics perspective and analyze how the three regimes reach the goals of compensation and prevention. The analysis will, hence, examine to what extent the systems under discussion create efficient incentives for prevention (6). The final section is the conclusion (7).

\section{The international regime}

\subsection{Legal basis of the regime}

In the 1960s, two international compensation regimes have been established for nuclear damage: The Organisation for Economic Co-operation and Development (OECD) regime on the one hand and the International Atomic Energy Agency (IAEA) regime on the other. Under the auspices of the Nuclear Energy Agency (NEA) of the OECD, the Convention on Third-Party Liability in the Field of Nuclear Energy of July 29, 1960 (Paris Convention) and the Brussels Supplementary Convention to the Paris Convention on Third-Party Liability in the Field of Nuclear Energy of January 31, 1963 (Brussels Supplementary Convention) have been developed. The IAEA developed the Vienna Convention on Civil Liability for Nuclear Damage of May 21, 1963 (Vienna Convention). The conventions of

Footnote 3 continued

represents a rapid increase in nuclear power in the next decades. See National Development and Reform Commission, Nuclear Power Medium and Long-Term Development Plan (2005-2020) (2007).

4 The "Reply to the Ministry of Nuclear Industry, the National Nuclear Safety Bureau and the State Council Atomic Energy Board in respect of Handling Nuclear Third Party Liability" of 1986 (the "1986 Reply") (issued by the State Council Guohan (1986) No. 44), and the "Reply to Questions on the Liabilities of Compensation for Damages Resulting from Nuclear Accident" of 2007 (issued by the State Council, Guohan (2007) No. 64) (the "2007 Reply"). An English unofficial translation of the 2007 Reply can be found at: http://www.oecd-nea.org/law/nlb/nlb-80/documents/103_104_TextChina.pdf.

5 We will systematically review the legal basis of the regime, the definition of nuclear damage, the scope of the liability regime, the question who can be held liable (including whether there is any channelling of liability) and finally the amount of compensation, including obviously who will generate this compensation.

6 Attention will be paid to the incentives particular regimes generate for operators of nuclear power plants to internalize the externalities generated through the nuclear risk. 
these two regimes together constitute what is often referred to as the first generation of nuclear liability conventions (Faure and Van den Borre 2008: 219).

There were no significant changes to the different nuclear liability treaties until after the Chernobyl accident on April 26, 1986 (Schwartz 2006: 41-44). The accident triggered a revision process for both the NEA and IAEA regimes, resulting in the adoption of several new international conventions. Those conventions are called the second generation of nuclear liability conventions, which consist of the Joint Protocol Relating to the Application of the Vienna Convention and the Paris Convention (Joint Protocol), the Protocol to Amend the 1963 Vienna Convention on Civil Liability for Nuclear Damage (the Protocol to the Vienna Convention), the Convention on Supplementary Compensation for Nuclear Damage (CSC), the Protocol to amend the Convention on Third-Party Liability in the Field of Nuclear Energy of July 29, 1960 (the Protocol to the Paris Convention) and the Protocol to Amend the Convention of January 31, 1963 Supplementary to the Convention of July 29, 1960 on Third-Party Liability in the Field of Nuclear Energy (the Protocol to the Brussels Supplementary Convention).

\subsection{Definition of damage}

Before analyzing the details of the international nuclear liability rules, one important issue, which needs to be clarified, is which type of damage is compensable. The Paris Convention limits the compensable scope to: "damage to or loss of life of any person" and "damage or loss of any property" not related to the installation (damage to the installations or on-site damage). ${ }^{7}$ It does not further explain what constitutes damage to persons or damage, but leaves it to the competent court. ${ }^{8}$ The Vienna Convention adopted a similar definition, but also allows the compensation of other types of loss or damage if the law of the competent court so provides. ${ }^{9}$ The limited compensable scope is broadened in the second generation of conventions. In addition to the two headings in the Paris Convention, the Protocol to the Paris Convention extends the scope of "nuclear damage" to include the economic loss arising from the first two headings, the costs of environmental reinstatement measures which are actually taken or to be taken; "loss of income deriving from a direct economic interest in any use of enjoyment of the environment" and the costs of preventive measures. ${ }^{10}$ A similar definition is also adopted in the Protocol to the Vienna Convention. ${ }^{11}$ This extension was made in response to the Chernobyl accident, which caused not only serious personal injury but also extensive environmental damage. ${ }^{12}$ The environmental damage is compensable to the extent that preventive measures and reinstatement measures are taken or to be taken. Pure economic loss may also be compensable if it derives from "a direct economic interest in any use or enjoyment of the environment." 13

\footnotetext{
7 Article III (a), the Paris Convention.

8 Paragraph 39, the Exposé des Motifs of the Paris Convention.

9 Article I (k), the Vienna Convention.

10 Article I (a) (vii), the Protocol to the Paris Convention.

11 Article I, 1 (k), the Protocol to the Vienna Convention.

12 Julia Schwartz (2006), at 46.

13 Article I (a) (vii), the Protocol to the Paris Convention.
} 


\subsection{Scope of liability}

All international conventions adopt a model of strict liability. According to the Paris Convention, the operator is liable for damage caused by a nuclear incident in a nuclear installation or involving nuclear substances coming from such installations. ${ }^{14}$ To prove the fault of nuclear operators is no longer necessary to establish liability. Liability established under the Paris Convention is quite stringent since many classical exonerations, such as force majeure, Act of God or intervening acts of third persons under general tort law are no longer applicable. ${ }^{15}$ The available exonerations are an act of armed conflict, hostilities, civil war and insurrection. The operator is not liable for damage caused via a grave natural disaster of an exceptional character unless the legislation of the Contracting Party in whose territory his nuclear installation is situated provides to the contrary. ${ }^{16}$ Similar stipulations about strict liability and exonerations can also be found under the Vienna Convention. ${ }^{17}$ However, under the Vienna Convention, there is an additional possibility for operators to be relieved of his liability: the competent court can, according to the applicable law, relieve the operator wholly or partly from his obligation if the operator can prove that damage resulted from gross negligence or an act or the omission of the victims. ${ }^{18}$ A grave natural disaster of an exceptional character is no longer a valid defense under the second generation of conventions. ${ }^{19}$

\subsection{Liable parties}

Under the Paris Convention, liability is channelled to the operators. In addition to the operators, no one else is liable for the damage caused by a nuclear incident. ${ }^{20}$ The "operator" is defined as "the person designated or recognized by the competent public authority as the operator of that installation." 21 On the basis of these provisions, other parties than the operator who would also engage in nuclear activities cannot be held liable, since the Paris Convention is the only legal basis for a claim against the nuclear operator in case of a nuclear accident. ${ }^{22}$ This concentration of liability is based on two reasons: to avoid the complicated legal procedures to identify the liable parties and to allow a concentration of insurance capacity. ${ }^{23}$ Under the Paris Convention, the operators in principle do not have a right of recourse against the other parties. This is because it is argued that allowing recourse will make it necessary for suppliers to seek insurance coverage and will lead to costly duplication of insurance. ${ }^{24}$ However, recourse is possible if the damage

\footnotetext{
14 Article III (a), the Paris Convention.

15 Point 48, the exposé des motifs of the Paris Convention.

16 Article IX, the Paris Convention.

17 Article I (1) (k), IV (1), (3), the Vienna Convention.

18 Article IV (2), the Vienna Convention.

19 Article IX, the Protocol to the Paris Convention; Article IV, the Protocol to the Vienna Convention.

20 Article VI (a), (b), the Paris Convention.

21 Article I (a) (vi), the Paris Convention.

22 Article VI (c) (ii), the Paris Convention.

23 Point 18, the exposé des motifs of the Paris Convention.

24 Point 15, the exposé des motifs of the Paris Convention.
} 
results from an act or omission done with intent to cause damage or if and to the extent provided by contract. $^{25}$ The Vienna Convention also has similar provisions. ${ }^{26}$

\subsection{Compensation}

\subsubsection{Financial cap on the operator's liability}

The liability of the nuclear operator is capped under the conventions. The Paris Convention sets the maximum liability of the operator at 15 million Special Drawing Rights (SDRs) (17.03 million Euro), but allows the Contracting Party to establish by legislation a greater or lesser amount considering the capacity of insurance and financial security. ${ }^{27}$ Many Contracting Parties set the limit higher than that set in the Paris Convention. For example, in Sweden, the limit on liability is set at 300 million SDRs (340.55 million Euro) according to the Nuclear Liability Act (SFS 1968:45) (OECD 2008: 13). Germany even adopted a system with unlimited liability. ${ }^{28}$ Under the Vienna Convention, the cap of liability should be no less than 5 million US dollars (5.68 million Euro). ${ }^{29}$

It is, however, important that in the second generation of nuclear liability conventions, a few important changes have been made. These refer inter alia to an increase in the amount of the limitation of liability. The Protocol to the Paris Convention increases the limit for nuclear operators to be no less than 700 million Euro. ${ }^{30}$ The Convention even allows the adoption of unlimited liability by the Contracting Parties, as long as the financial security required is no less than the amount mentioned above. ${ }^{31}$ The compensation capacity also increased under the IAEA regime. The Protocol to the Vienna Convention increases the liability limitation to no less than 300 million SDRs(340.55 million Euro), or no less than 150 million SDRs (170.27 million Euro), provided the Installation State will make public funds available to cover the amount between the set the limitation to 300 million SDRs (340.55 million Euro). ${ }^{32}$

\subsubsection{Company insurance}

To seek financial security coverage for the operator's liability is important for international regimes of nuclear liability. Both conventions require the operator to have and maintain insurance or other financial security up to the cap of its liability. ${ }^{33}$ Insurance is the most

\footnotetext{
25 Article VI (f), the Paris Convention.

26 Article II (5), X, the Vienna Convention.

27 Noticing that The Contracting Party can also require a lower amount according to the nature of the installation. The lower amount should be no less than 5 million SDRs (5.68 million Euro). Article VII (b), the Paris Convention.

${ }^{28}$ Gesetz über die friedliche Verwendung der Kernenergie und den Schutz gegen ihre Gefahren (Atomgesetz-AtG) vom 23. December 1959, Neufassung vom 15 Juli 1985, letzte Änderung vom 31 Juli 2011, (Act on the peaceful utilization of nuclear energy an the protection against its hazards (Atomic Energy Act) of 23 December 1959, as amended and promulgated on 15 July 1985, last amendment of 31 July 2011), § 31.

29 Article V, the Vienna Convention.

${ }^{30}$ Noticing that The Contracting party can reduce the liability to be no less than 70 million Euro for an incident originating from a nuclear installation, or to be no less than 80 million Euro for the carriage of nuclear substances according to the reduced risks. Article VII (a) (b), the Protocol to the Paris Convention.

31 Article X (b), the Protocol to the Paris Convention.

32 Article V (1), the Protocol to the Vienna Convention.

33 Article X, the Paris Convention; Article VII, the Vienna Convention.
} 
popularly used instrument for an operator to cover its liability. In fact, the cap on liability is usually set as the maximum available amount from the insurance market. It is for the Contracting Parties to decide the nature, form and extent of the compensation according to applicable national law. ${ }^{34}$

\subsubsection{Public funding}

To provide the potential victims better protection, the Brussels Complementary Convention was established under the auspices of the NEA in 1963. Under the Brussels Complementary Convention, two additional layers of compensation are added in terms of public funds. Therefore, the total amount of money available for compensation is increased to 300 million SDRs (340.55 million Euro), and a third-layer compensation system is established: firstly, the operator is liable up to an amount of at least 5 million SDRs (5.68 million Euro) via its financial security; between this amount and 175 million SDR (198.65 million Euro), the Installation State needs to make public funds available; for the amount between 175 and 300 million SDRs (198.65 and 340.55 million Euro), compensation is made out of public funds by all Contracting Parties according to a specific formula. ${ }^{35}$ The Installation State can escape its obligation under the second layer by setting the liability limit at no less than 175 million SDRs (198.65 million Euro). In that case, the whole amount up to 175 million SDRs (198.65 million Euro) needs to be made available by liable operators. Therefore, a three-tier compensation system was established.

Moreover, the amounts of public funding in the second and third tier of compensation have also been changed in the second generation of nuclear liability conventions. From the maximum amount of operators' liability set by the Protocol to the Paris Convention up to 1,200 million Euro, the Installation State needs to pay in terms of public funds. Public funds need to be made available by all Contracting Parties according to a set formula of compensation between the amounts of 1,200 million Euro and 1,500 million Euro. ${ }^{36}$ Thus, the available resources for compensation in case of a nuclear accident are increased significantly: from 300 million SDRs (340.55 million Euro) to 1,500 million Euro.

As we just mentioned, also the Protocol to the Vienna Convention introduced a second layer of compensation by forcing the Installation State to make public funds available to cover the amount between the limitation and 300 million SDRs (340.55 million Euro). However, although the amount is also significantly increased, it is modest compared with the possible significant damage and it is just set at the same level as the original Paris Convention and the Brussels Supplementary Convention. The CSC Convention also provides two tiers of compensation: a first 300 million SDRs (340.55 million Euro) is paid by public funds from the Installation State and another 300 million SDRs (340.55 million Euro) from the collective funds from the Contracting Parties. ${ }^{37}$

These new conventions and protocols are designed to overcome the deficiency of the first generation of nuclear liability conventions. However, the revisions have made eight international conventions available for nuclear liability, which lead to the so-called a "labyrinth of international conventions" dealing with nuclear liability issues (Duncan 2008: 85). Moreover, the actual influence of the five new conventions is still

\footnotetext{
34 Article XI, the Paris Convention; Article VIII, the Vienna Convention.

35 Article III (a) (b), the Brussels Complementary Convention.

36 Article III (b), the Protocol to the Brussels Complementary Convention.

37 Article III 1, IV 1, the CSC Convention.
} 
limited. ${ }^{38}$ There are still many large nuclear generating countries which are not a member of any of those conventions, such as the US, Canada, Japan, China, Korea, Russia, South Africa and Switzerland.

\section{Japan}

\subsection{Legal basis of the regime ${ }^{39}$}

Nuclear energy is an important energy source in Japan. It is reported that as of 2009, "fiftyfour commercial nuclear power plants are operating at 17 stations with a total licensed generating capacity of 48,847 MWe which was approximately $20 \%$ of the total capacity of electric power generation"(Japan Nuclear Energy Safety Organization 2010: 1). In a country like Japan, where nuclear energy is so prominent, the liability system to prevent and compensate nuclear damage is extremely important. Japan does not participate in any international convention on civil liability for nuclear damage. Japan has not felt the need to join international conventions, since other major nuclear powers, such as the US, India and China, were not party to the international nuclear liability conventions either. ${ }^{40}$ Japan established its own national regime through four major legislative instruments: the Act on Compensation for Nuclear Damage ("Act on Compensation") (promulgated in 1961 and recently revised in 2009), the Order for the Execution of the Act on Compensation for Nuclear Damage ("Order on Compensation") (promulgated in 1962 and recently revised in 2009), the Act on Indemnity Agreement for Compensation of Nuclear Damage ("Act on Indemnity") (promulgated in 1961 and recently revised in 2009) and the Order for the Execution of the Act on Indemnity Agreement for Compensation of Nuclear Damage ("Order on Indemnity") (promulgated in 1962 and recently revised in 2009). ${ }^{41}$ A number of principles of the international third-party liability regimes are embodied in those laws.

The Act on Compensation for Nuclear Damage of 1961 shapes the major structure of the liability rules for nuclear damage and the corresponding financial requirements. ${ }^{42}$ The Act on Compensation was initially passed in 1961 and was amended in $2009 .^{43}$

\subsection{Definition of damage}

The Act on Compensation defines "nuclear damage" as "any damage caused by the effects of the fission process of nuclear fuel, or of the radiation from nuclear fuel etc., or of the toxic nature of such materials." 44 The damage suffered by the liable nuclear operator is

\footnotetext{
38 Among the five new conventions, only two have come into force: the Joint Protocol entered into force in 1992 and the Protocol to the Vienna Convention came into force in 2003. Until now (January 2013), only 5 countries have ratified the protocol to the Vienna Convention Schwartz (2009), 50.

39 For a detailed analysis of the compensation system for nuclear damage in Japan as well as of the Fukushima incident, Weitzdörfer (2011)

40 Telephone Interview with Mr. Kuni Shimada, Principal International Policy Coordinator, Global Environment Bureau, Ministry of Environment (Japan) (Dec. 26, 2011).

41 Copies of English translations can be found at the website of NEA; see Japan, Nuclear Energy Agency, http://www.oecd-nea.org/law/legislation/japan.html (last visited Nov. 2, 2012).

42 Genshiryoku Songai no Baisho ni Kansuru Houritsu [The Act on Compensation for Nuclear Damage], Law No. 147 of 1961, amended by Act No. 19 of 2009 (Japan).

43 Id.

44 Id. $\S 2$ (2).
} 
excluded. ${ }^{45}$ This definition is made from the perspective of the cause of the damage but is silent on which specific types of damage are compensable. Hence, it is unclear whether the liability of the operators also extends to consequential economic losses and to environmental costs. The question that types of damage are compensable under the nuclear law in Japan can only be answered by exploring the practice. The compensation for Fukushima accident constitutes such an example and will the analyzed in the following section.

\subsection{Scope of liability}

As in the international regime, a strict liability regime for nuclear damage is established in Japan. ${ }^{46}$ The title mentions that it is a "liability without fault." If the nuclear damage is caused by a "grave natural disaster of an exceptional character or by an insurrection," the nuclear operator can be exonerated from liability. ${ }^{47}$ The phrase "of an exceptional character" is essential to determine the exoneration of liability in the context of the Fukushima accident. ${ }^{48}$ Nuclear operators can still be held liable for the nuclear damage caused by an ordinary natural disaster, such as earthquake or volcanic eruption, but they can cover such losses through an indemnity agreement with the government. ${ }^{49}$

\subsection{Liable parties}

In Japan, the liability is in principle also channelled to the nuclear operator ${ }^{50}$ However, if the damage is caused by the willful act of a third party, the operator who has compensated the damage has a right of recourse against the third party. ${ }^{51}$ Moreover, a nuclear operator can enter into a "special agreement with any person regarding rights of recourse." 52 In other words, through a special contractual arrangement, a nuclear operator has the possibility to recover damages from the contractors who actually contributed to the risks, including plant designers or builders.

\subsection{Compensation}

\subsubsection{Unlimited liability of the operator}

A major difference between the Japanese regime and the international regime is that in Japan the liability of the nuclear operator is unlimited.(Vásquez-Maignan 2011: 9)Although there is a minimum for the requirement of financial security that has to be provided by the operator, he is still liable for damage in excess of this amount. ${ }^{53}$

\footnotetext{
45 Id.

46 Section 3, the Act on Compensation for Nuclear Damage.

47 Id. $\$ 3$.

48 See infra Sect. 3.6.

49 Section 10, the Act on Compensation for Nuclear Damage.

50 Section 4 of the Act on Compensation for Nuclear Damage holds: "Where nuclear damage is covered by the preceding section, no other person other than the nuclear operator who is liable for the damage pursuant to the preceding section shall be liable for the damage".

51 Id. $\S 5$.

52 Id.

53 Sections 6-7, the Act on Compensation for Nuclear Damage.
} 


\subsubsection{Compulsory financial security}

Financial security provided by operators can be used to guarantee the availability of a certain level of assets in case of damage. The Act on Compensation imposes on the nuclear operator's obligations to provide financial security up to a certain level. ${ }^{54}$ The financial security is set at 120 billion yen ( 0.95 billion Euro) for each installation or site or nuclear powered ship, though the cabinet order may provide for a lower amount. ${ }^{55}$ The operator can satisfy his financial obligation by using a contract of liability insurance for nuclear damage, an indemnity agreement with the government or a deposit approved by the Ministry for Education, Culture, Sport, Science and Technology ("MEXT"). The nuclear liability insurance policy is provided by the Japan Atomic Energy Insurance Pool ("JAEIP"). The insurance policy excludes several kinds of damage: the damage caused intentionally by the insured; a grave natural disaster of an exceptional character or by an insurrection; the use of atomic energy for non-peaceful purposes, earthquake, fire or tsunami; damage to the property owned, used or managed by the insured. ${ }^{56}$ When the damage is not covered by insurance or financial security, the operator can enter an indemnity agreement with the government to cover those losses. To seek the coverage of an indemnity agreement, the operator has to pay the government an indemnity fee. ${ }^{57}$

\subsubsection{Public funding}

This means that the Japanese state intervenes in the compensation for the victims of a nuclear accident on the basis of an indemnity agreement for which the operator pays a fee to the state. Moreover, the total coverage of 120 billion yen ( 0.95 billion Euro) is not a maximum but rather a minimum amount, to be covered via a combination of insurance and indemnity agreements. ${ }^{58}$ If the damage is still higher, the state could intervene under Section 16 of the Act on Compensation. ${ }^{59}$. Further state intervention is possible on the basis of a political decision. ${ }^{60}$ This provision comes into play where an operator could become insolvent if liability is too high. Unlike an indemnity agreement with the government, under which the actual rights and obligations of the government and the operator have been clearly established and the indemnity amount is determined before a disaster, aid distribution in these cases is not clear and is to a large extent determined ad hoc by the government. These ad hoc arrangements do not require the operators to pay a price for such aid.

\footnotetext{
${ }^{54}$ Section 6 the Act on Compensation for Nuclear Damage.

55 Id. § 7.1 .

${ }^{56}$ Liability Insurance for Nuclear Installations, Common Clause 2000, art. 7, cited in Hirokazu (2000).

${ }^{57}$ Order for the execution of the act on indemnity agreements for compensation of nuclear damage.

58 Section 7, the Act on Compensation for Nuclear Damage.

${ }^{59}$ Section 16 states: [w]here nuclear damage occurs, the Government shall give a nuclear operator (except the nuclear operator of a foreign nuclear ship) such aid as is required for him to compensate the damage, when the actual amount which he should pay for the nuclear damage pursuant to Section 3 exceeds the financial security amount and when the government deems it necessary in order to attain the objectives of this act. Act on Compensation for Nuclear Damage § 16(1).

${ }^{60}$ Indeed, Section 16(2) of the Act on Compensation provides that this aid shall be given to the extent that the government is authorized to do so by decision of the National Diet. Ultimately, the decision is the Japanese parliament's. Section 16(2), the Act on Compensation for Nuclear Damage.
} 
3.6 Case study: compensating the Fukushima accident

The Japanese compensation system is not only a legal framework on paper, but has also been tested in practice. Following the 9.0 magnitude earthquake at the east coast of Japan on March 11, 2011, a serious nuclear accident hit the Fukushima Daiichi power plant operated by the Tokyo Electric Power Company (TEPCO). This was caused by the failure of cooling system, of which the backup generators were located in the basement of the turbine building and were flooded by the tsunami following the earthquake. The failure of cooling system later led to core meltdown in three reactors. This accident was classified as International Nuclear Event Scale (INES) 7, parallel with only the Chernobyl Accident in the history of nuclear industry. ${ }^{61}$ This major accident was a consequence of the significant earthquake and tsunami, which immediately led to the question whether the tsunami can be qualified as "a natural disaster of an exceptional character," as a result of which the operator TEPCO can be exonerated from liability. Though the final judgement on this point lies in the hands of the court, the Japanese government was reluctant to admit the disaster to be "of an exceptional character" and required TEPCO to be fully responsible for the damage. This can be explained by the vulnerability of Japan to earthquake risks, including even a significant one. Besides, some even argued that experts had warned that an earthquake might lead to a nuclear incident in the Fukushima power plant and that TEPCO should be aware of such a risk (Weitzdörfer 2011).

Another related issue concerns the liable party, since the law channelled liability to the operators. However, a careful examination of the Fukushima accident shows that the designer of the power plant can contribute to the risk as well. The designer, General Electric (GE), placed all the backup generators at the turbine building, which is quite venerable to flooding risks. It is even reported that GE was warned of the design flaws in the 1970s (Mosk 2011). This, however, did not lead to improved safety in Fukushima Daiichi power plant.

To ensure a prompt and smooth compensation, a Dispute Reconciliation Committee for Nuclear Damage Compensation was established shortly after the accident. ${ }^{62}$ It has published several guidelines on determining the scope of compensable damage, which provides a quite broad coverage, including personal damage, property damage and even some pure economic losses. ${ }^{63}$ Though such guidelines are not legally binding, it will "serve as reference for the damage compensation negotiations between the victims and the nuclear operator and thus will facilitate smoother settlement negotiations between the parties" (Nomura et al. 2012: 22,23).

The guidelines of the Dispute Reconciliation Committee make no direct reference to the concept of environmental damage. In order to promote the cleanup of the environmental damage, a specific act was enacted on August 26, 2011: the Act on Special Measures concerning the Handling of Environmental Pollution by Radioactive Materials Discharged

\footnotetext{
61 The IAEA introduced INES system in 1990 to classify the significance of nuclear and radiological events. According to INES, events are divided into seven levels, with ten times difference in severity between each adjacent scale levels. See the website of IAEA: http://www.iaea.org/Publications/Factsheets/English/ines. pdf.

62 Such a committee was established according to the Act on Compensation, which allows the establishment of such an organization to be "in charge of mediating reconciliation of any dispute arising from compensation of nuclear damage and of preparing general instructions to help operators reach a voluntary settlement of such disputes". See Act on Compensation, Section 18 (1).

${ }^{63}$ For example, the guidance allows compensation for business damage, damage due to rumors and indirect damage. Physical damage is not required to award compensation for such titles of damage.
} 
by Nuclear Power Station Associated with the Tohoku District-Off the Pacific Ocean Earthquake that Occurred on March 11, 2011. This Act requires the national government, local governments and nuclear operators to decontaminate the pollution caused by Fukushima accident. It focused on reducing the influence of pollution on human health but not on providing compensation for complete cleanup of the environment (Faure and Liu 2012: 196-198).

Though liability in the Act of Compensation is uncapped, the amount of financial security is set at 120 billion yen, which is far from sufficient to cover the whole risk. The above analysis shows that government can decide to provide aid to the operator when the damage exceeds the available financial security. Not surprisingly, after such a catastrophe, the capacity of TEPCO to provide full compensation was limited and the government decided to intervene. This was achieved through the promulgation of the Act to Establish the Nuclear Damage Compensation Facilitation Corporation (the Corporation Act) of August 3, 2011 This act establishes a nuclear damage compensation facilitation corporation (the Corporation) to on the one hand promote the damage compensation and on the other hand to help the stabilization of the nuclear power station and electricity supply. ${ }^{64}$ Under such Act, an ex post risk-sharing system is established. Nuclear operators need to make contributions to this corporation, which will be put into the reserve fund. In case of need, the corporation will provide ordinary assistance from the reserve fund. When the corporation does not have sufficient reserve fund to cover the damage, special assistance can be provided with the approval of the competent minister. Under this plan, the corporation can get support either from government bonds or from financial institutions with a guarantee from the government. The liable nuclear operator, after receiving special financial assistance, shall pay special contributions back to the corporation in the following years.

\section{China}

\subsection{Legal basis of the regime}

Just like Japan, China is also not a member to any of the international liability conventions. There is also no legislative document which can be called the Act that stipulates specifically how nuclear liability is regulated in China. The main rules concerning nuclear liability are to be found in two so-called replies, published by the State Council: the "1986 Reply" and the "2007 Reply." The effectiveness of those two replies and their place in the hierarchical system of legal norms in China will be addressed below.

An interesting aspect of nuclear liability in China is that there is no specific act dealing with nuclear liability. However, other acts often do not exclude nuclear installations from their application. ${ }^{65}$ Hence, in addition to the two so-called replies, which were just mentioned, also other, more general, statutes could play a role in compensating victims of nuclear accidents as well. For example, general tort rules could also be applicable such as the General Principles of Civil Law (GPCL), ${ }^{66}$ but also the new Tort Liability Law which

\footnotetext{
64 Article 1, the Act to Establish Nuclear Damage Compensation Facilitation Corporation.

65 This is different in other jurisdictions, e.g. the European Directive concerning Environmental Liability explicitly excludes nuclear risks and ecological damage resulting from nuclear activities from the scope of the directive (art. 4.4 of Directive 2004/35/EC of 21 April 2004, Official Journal L143 of 30 April 2004, 56).

66 [The General Principles of Civil Law] (promulgated by the Nat'l People's Cong., April 12, 1986, effective Jan. 1, 1987) art. 106 (China).
} 
was introduced in China in December 2009 (Faure and Weiqiang 2011: 225). Under the GPCL, the general provisions concerning civil liability (Article 106) and concerning environmental liability (Article 124) do not exclude nuclear liability from their application. The general provisions under the new Tort Liability Law of $2009^{67}$ can also apply to nuclear liability. Furthermore, article 70 of the Tort Liability Law provides an explicit legal basis for nuclear liability:

If a nuclear accident from a nuclear installation leads to third-party damage, the nuclear operators shall be liable, unless he can prove the damage is caused by war or caused by the victims on purpose.

This was actually the first time that nuclear liability is explicitly prescribed at the level of a statute, rather than merely in normative rules issued by the government. ${ }^{68}$ However, it does not specify the concrete content of the liability rule. There is no information on issues such as the scope of compensable damage, whether liability is limited, who is a nuclear operator etc. The details of the applicable liability rules are mainly reflected in the two replies by the State Council mentioned above. Those two replies were issued by the State Council to ease the concerns of foreign nuclear suppliers about their potential nuclear liability in China. (Cai 2004: 291-292;Vásquez-Maignan 2010: 20-22)

A formal problem is, however, that those replies are not formal administrative regulations published by the state council which need a much more formal and sophisticated promulgation procedure. This hence raises questions concerning the binding force of both replies. ${ }^{69}$ Nevertheless, they do contain most of the legal rules on the basis of which the scope of nuclear liability in China can be determined. The same as in the relationship between the GPCL and the Tort Liability Law, the 2007 Reply has the priority over the 1986 Reply. However, if one issue is addressed only in the 1986 Reply, this provision still applies.

\subsection{Definition to damage}

As mentioned earlier, article 70 of the Tort Liability Law is the basic law applying specifically in case of nuclear damage. But it does not define what constitutes nuclear damage. The scope of compensable damage is only explicitly discussed under the 2007 Reply. According to article 2 of the 2007 Reply, the compensable damage includes "personal casualties, property losses or environmental damages arising out of nuclear accidents." However, this provision is still vague, especially with regard to the implication of "environmental damage." It can be explained narrowly to include only personal injury

${ }^{67}$ [Tort Liability Law of the People's Republic of China] (promulgated by the Standing Comm. Nat'l People's Cong. Gaz., Jan. 1, 2010, effective July 1, 2010) art. 70 (China).

${ }^{68}$ Note that the promulgation of the Tort Liability Law does not mean that the GPCL becomes invalid. See article 83 of the Law on Legislation of China: "In the case of national law, administrative regulations, local decrees, autonomous decrees and special decrees, and administrative or local rules enacted by the same body, if a special provision differs from a general provision, the special provision shall prevail; if a new provision differs from an old provision, the new provision shall prevail." [Law on Legislation] (promulgated by the Standing Comm. Nat'1 People's Cong., Mar. 15, 2000, effective July 1, 2000) 2000 Standing Comm. Nat'l people's cong. GAz. 112, art. 2 (China). Hence, article 70 is the special and new law. It shall have the priority when applied to nuclear damage. For issues not addressed by it, the GPCL still applies.

69 According to Chinese "Law on Legislation", administrative regulations are formal legal sources and their issuance needs a formal and sophisticated promulgation procedure. Hence the two replies are not administrative regulations, but only normative rules. They can only be used as sources of argument but not the sole sources of the judgement. For a detailed discussion about the binding focus of the two replies, see Liu and Faure 2012, Section III, B. 
and property damage caused via the environment or broadly to include also the damage to the environmental itself. If the broader definition is adopted, the enjoyment of the environment, costs of preventive measure and restoration measures can also be compensable. Hence, to understand the meaning of "environmental damage," one needs to look at general civil law and environmental law. However, an examination of the related law shows that with the exception of the Marine Environmental Protection Act, it is unclear whether the damage to the environment itself is compensable (Liu and Faure 2012: 801-802).

\subsection{Scope of liability}

Strict liability is also adopted in China's liability regime for nuclear damage. The 1986 Reply prescribes that the operators bear strict liability for nuclear damage. Although the term is not used in the 2007 Reply, it does not require fault to establish liability for operators. Also, article 70 of the new Tort Liability Law follows a strict liability rule by holding that the operator where a nuclear accident happens shall be liable unless he can prove that such harm was caused by war or inflicted by the victim intentionally.

The liability both on the basis of the replies and in the Tort Liability Law of 2009 is quite strict. The only available defense would be that the damage is caused by a nuclear accident directly resulting from armed conflict, hostile action, war or riot. The Tort Liability Law of 2009 adds harm that would be inflicted intentionally by the victim as a defense. The 1986 Reply also allows "a grave natural disaster of an exceptional nature" as a defense. But this defense is no longer available under the 2007 Reply.

\subsection{Liable parties}

The replies adopt the principle of channelling of liability: Only nuclear operators are liable; all other parties are exonerated from liability. The 1986 Reply has no provision about the right of recourse, but recourse is allowed under the 2007 Reply under certain conditions: If a written contract between an operator and another person provides for the right of recourse, the operator may recourse against the other person after compensating the victim; the operator may also have the right of recourse if the damage is caused by a third party's willful act or omission. ${ }^{70}$

Besides, under the Tort Liability Law of 2009, nuclear liability is also imposed on nuclear operators. As discussed in Section 4.2, article 70 prescribes nuclear liability, and this article is located in chapter nine on ultra-hazardous liability. Thus, both the general provisions in this chapter and the specific provision on nuclear liability may apply. The general provisions prescribe that the parties taking ultra-hazardous activities shall be liable for damage they caused. ${ }^{71}$ Article 70 requires nuclear operators to be liable for nuclear damage. However, it does not explain the term "nuclear operators." Moreover, the Tort Liability Law does not exclude the liability of other parties. ${ }^{72}$ The Product Quality Act

\footnotetext{
70 Article 9, the 2007 Reply.

71 Article 69, Tort Liability Law.

72 It is worth noting that the channeling of liability under the two replies is potentially in contradiction to the Product Quality Act (the PQA), which holds the producer of a defective product liable for personal injury and other property damage caused by the defect. (Article 41-42 of the PQA) If these provisions apply to nuclear cases, the nuclear suppliers may be held liable if they also contribute to the nuclear damage.
} 
$(\mathrm{PQA})^{73}$ even provides principles in contradiction to the channelling of liability. The PQA requires the producer of the defective product be held liable for personal injury and other property damage caused by the defect. ${ }^{74}$ Therefore, the other parties in addition to nuclear operator might be held liable according to the PQA.

\subsection{Compensation}

\subsubsection{Financial cap on the operator's liability}

The liability of nuclear operators is limited in amount. Under the 1986 Reply, the operators' liability is capped at 18 million RMB (5.21 million US dollar 1986). ${ }^{75}$ The 1986 Reply does not differentiate between the different types of operators. The 2007 Reply set the cap of liability according to the risks different operators pose: the operators of nuclear power plants and the operators of spent fuel storage, transportation and post-treatment are liable up to RMB 300 million (35.53 million Euro); other operators are only liable up to RMB 100 million (11.83 million Euro). ${ }^{76}$

As far as the Tort Liability Law is concerned, in both the general parts (chapter I-IV) and chapter VIII (environmental liability), there is no provision concerning a cap on liability. Caps are allowed in chapter IX (liability for ultra-hazardous activities). According to article 77, if other acts allow for a cap on liability for ultra-hazardous activities, the other acts shall apply. However, the problem arises that these two replies are only normative rules, but not formal statutes arises again.

\subsubsection{Compulsory financial security}

The 1986 Reply has no specific requirements about financial security. However, with the fast development of China's nuclear industry and the increased liability cap, the necessity of financial security started to receive more attention. In the 2007 Reply, the operators are required to make appropriate financial arrangements to ensure timely and effective compensation in case of damage. Before the operation of a nuclear power plant or the storage, transportation or post-treatment of spent fuels (not the construction of the power plant), the operator must purchase sufficient insurance to cover its limits of liability. ${ }^{77}$ The 2007 Reply does not further clarify which kind of financial security mechanisms can be used. In practice, all the operators of nuclear power plants choose to realize their financial responsibility by seeking liability insurance coverage (Jia 2011: 48).

\subsubsection{Public funding}

In addition to the cap on liability, the replies require the government to provide indemnity. For example, under the 1986 Reply, if the nuclear damage exceeds the cap of liability

\footnotetext{
73 [Product Quality Law] (promulgated by the Standing Comm. Nat'l People's Cong., Feb. 22, 1993, effective Sept. 1, 1993) art. 73 (China)

74 Article 41, the PQA.

75 Article 3, the 1986 Reply.

76 Article 7, the 2007 Reply.

77 The amount of financial security should be sufficient to cover the cap of their liability. See Article 8 , the 2007 Reply.
} 
(RMB 18 million), the government shall provide necessary indemnity up to RMB 300 million (86.89 million US dollar 1986). Under the 2007 Reply, the government indemnity is increased to RMB 800 million (94.56 million Euro). The 2007 Reply also allows additional financial indemnity if the damage is resulting from an extraordinary nuclear accident and the increase is approved by the State Council. ${ }^{78}$

\section{Comparative analysis}

We have focused on some of the main features of the nuclear liability schemes in the international regime (2), Japan (3) and China (4). A comparison between the nuclear liability scheme in the international, Japanese and Chinese regimes is quite interesting. Japan and China are not a member of the international regime, whereas they are (Japan) or will be (China) quite significant as far as the use of nuclear energy is concerned.

We will briefly compare the three regimes as far as the discussed aspects (definition of damage, scope of liability, liable parties and amount of compensation) is concerned; in the next section (6), we will evaluate the nuclear liability regimes also normatively using economic analysis of law.

\subsection{Definition of damage}

The first issue to be compared is which type of damage is compensable under three regimes. The international regime is the only one which provides a clear definition. The first generation of conventions focuses on damage to persons and property. The compensable scope is broadened significantly in the second-generation conventions. Consequential economic losses are compensable. Compensation for the loss of income as a result of the loss of use or enjoyment of the environment is also allowed. Environmental damage is compensable, but limited to the costs of preventive and reinstatement measures. The definition of "nuclear damage" in Japan is silent on the scope of compensable damage. The examination of the Fukushima Accident shows that the damage is explained broadly in practice to include pure economic losses and some of the cleanup costs for environmental damage. In China, nuclear operators are liable for personal casualties, property losses and environmental damage. However, the scope of these concepts needs further clarification.

\subsection{Scope of liability}

As far as the scope of liability is concerned, there are in fact not major differences between the three regimes examined. All adopt a strict, no-fault liability regime for nuclear accidents. The Japanese system, first generation of international conventions and the 1986 Reply in China allow an exception from liability in case the accident would be caused by "a grave natural disaster of an exceptional nature." However, under the second generation of international conventions and the 2007 Reply in China, this defense is abrogated. However, the recent experience with the Fukushima incident in Japan following the tsunami of March, 11, 2011, shows that it may not be easy for a nuclear operator to call on "a grave natural disaster of an exceptional nature".

78 Article 7, the 2007 Reply. 


\subsection{Liable parties}

All regimes examined channel liability to the operator of the nuclear power plant. However, there are quite a few differences as far as the extent of the channelling is concerned. In the international regime, the channelling seems to be absolute: only the operator and no other party can be held liable. Recourse is only possible if the damage results from an act or omission done with intent to cause damage or if and to the extent provided by contract. A similar construction can be found in Japan where recourse would be possible on the basis of a "special agreement with any person regarding rights of recourse." Again, a similar model is followed in China where recourse is possible on the basis of a written contract. However, in China, the situation is rather unclear since nuclear liability is also regulated in the Tort Liability Law of 2009 of which article 70 holds nuclear operators liable without specifying that this would exclude the liability of other parties. The potential application of the PQA may even broaden the scope of liable parties. China may hence have a more limited scope of the channelling than the international regime or Japan.

\subsection{Compensation}

In fact, the three regimes are still pretty comparable as far as the scope of liability and the liable parties are concerned. Most differences become apparent when the question is concerned how much compensation is available for the victims of a nuclear accident and who will finance this compensation. The general starting point in the international conventions and China is that the liability exposure of the nuclear operator is capped. In the second-generation conventions, the cap has been substantially increased and member states could opt for unlimited liability. One should, however, bear in mind that most of these international conventions have not entered into force yet. As far as China is concerned, it is unclear whether the nuclear operators in China would be exposed to capped liability under the replies or an unlimited liability on the basis of the Tort Liability Law of 2009. The situation in Japan is clear to the extent that the liability of the nuclear operator is unlimited (Vásquez-Maignan 2011: 9). There is only a minimum amount of financial security to be provided by the operator, but the operator remains liable for the damage in excess of this amount.

The three regimes have a duty imposed upon the operator to provide financial security. In the international regime, the security has to be provided to the amount of the cap. The amount to be provided for financial security in Japan is currently set at 120 billion yen ( 0.95 billion Euro) after the last increase in 2009. In China, operators are required to make appropriate financial arrangements, but it is not specified what kind of financial security mechanisms can be used, so that uncertainty remains in that respect. A striking feature of the regime in Japan is that the financial security cannot only be provided via insurance, but also via a deposit approved by the minister or via an indemnity agreement to be provided by government. Such an indemnity agreement is not an outright subsidy but indemnity provided by government for which the operator pays an indemnity fee. This is a fundamental difference with the international regime where large amounts of public funding are provided in the so-called second and third tier for which the operator does not have to pay. Under the international regime, nuclear energy is hence subsidized via state provided guarantees. ${ }^{79}$ This is the same in China where the government is also required to provide

${ }^{79}$ It is worth noting that the extent of the subsidy also depends on the way the fund is financed. If it is financed through the general revenues, more inefficiencies are caused. If it is the polluters who pay for it, 
support without operators having to pay a fee. However, there is still a subsidy effect in Japan as well since in addition to the indemnity agreement, the Japanese state will still intervene in case the available financial security is not sufficient to compensate the victims. In that case, the government could still take the necessary steps to provide relief to victims for which the operator will not have to pay a price. The recent incident at Fukushima makes clear that not only the government, but also other nuclear operators (via resource pooling) will intervene to compensate the victims. Hence, also in Japan, in case of a largescale nuclear disaster (of the Fukushima type), a bailing out of the nuclear operator will take place (Faure and Liu 2012, 198-201).

\section{Critical economic analysis}

\subsection{Scope of liability}

After this brief comparison of the three regimes, also an evaluation can be carried out, using economic analysis. The three regimes apply a strict liability regime which makes perfect economic sense. Strict liability, so it is often held in the literature (see, e.g., Shavell 1980) will lead to optimal incentives for care and activity levels of nuclear operators. By exposing a power plant operator to strict liability, a full internalization of the externality caused by the nuclear accident can be generated. The fact that the second-generation international conventions also exclude "a grave natural disaster of an exceptional nature" as a defense can only be welcomed from an economic perspective. This change can be desirable since it will provide incentives to operators to construct an operator nuclear installation more carefully to make them more disaster resistant. Again, the recent incident at the Fukushima plant in Japan makes clear that this is absolutely necessary. The Japanese government therefore rightly rejected to recognize the Fukushima incident as a "grave natural disaster of an exceptional nature."

\subsection{Liable parties}

An aspect that has already received much criticism is the exclusive channelling of the civil liability to the operator of the nuclear power plant (Faure and Fiore 2008: 229-30). The problematic aspect of channelling is that it excludes the liability of others who could have contributed to the risk as well (Trebilcock and Winter 1997: 215). In theory, operators could negotiate with other parties and make agreements to abolish the channelling. However, a recent survey shows that the differences in bargaining power between the operators and, e.g., the designers or constructors make it in fact impossible for them to impose liability on others (Ameye 2010: 56). The case of the recent Fukushima incident shows the potentially catastrophic effects of an exclusive channelling to the operator of the nuclear power plant.

Footnote 79 continued

then it is not a subsidy anymore. One such example exists in the US. It ratified the CSC in 2008, under which it has the obligation to make 300 million SDRs available in case of an accident happening on its territory. However, this ratification of the CSC relieves the suppliers from potential liability for foreign victims; the suppliers are required to participate in a retrospective risk pooling program to cover the contribution of the US according to the CSC. Thus it are actually the polluters, rather than the public, who finance the compensation. See: Energy Independence and Security Act of 2007, Pub. L. No. 110-140, § 934 (a) (1) (D), 121 Stat. 1492, 1744 (2007). 


\subsection{Compensation}

Economic analysis also makes clear that for strict liability to work efficiently the amount of compensation should be equal to the actual costs of the accident (Schäfer and MüllerLanger 2009). Under the international nuclear conventions and in the Chinese regime, the liability is capped. This not only leads to undercompensation of victims; liable parties will also have reduced incentives to prevent the damage to the extent of the cap. Though the financial cap under the international conventions has been increased through the years and they allow the member states to adopt unlimited liability, only a limited number of countries adopted unlimited liability in practice. ${ }^{80}$ The amounts set under the protocols are still nowhere near to the real possible costs of a major nuclear accident. The Chinese liability cap is even lower. Though there is no consensus on the estimation of the costs of the worst nuclear accidents yet, the Chernobyl accident and Fukushima accident have caused damage much higher than the limit set in nuclear conventions. Some studies also estimate the possible damage to be as high as several billions of Euros: It is estimated that the total damage of a reactor meltdown in Germany would be over 5,000 billion euro; a Greenpeace review of the costs cited some estimations, varying from several billion to 6.8 trillion US dollars (Duncan 2008: 92). Given the potential catastrophic losses the nuclear accidents can create, the limited liability creates a substantial subsidy to the nuclear industry. This subsidy, may not only lead to less than efficient care level adopted by operators, but also makes nuclear energy in an advantageous status compared with other kinds of energy. This may lead to a too high demand for nuclear energy as well (Faure and Fiore 2009: 419).

Also in this respect, Japan provides an interesting example. First, Japan has, differently from the international regime and in China, adopted a principle of unlimited liability. Second, the amount of the required financial security in Japan is similar to the second generation of the international regime. Although no preset cap on liability exists in the Act on Compensation, limited liability under corporate law may prevent the nuclear industry from internalizing the full cost of injuries they cause. An analysis based on a privateinterest approach to compensation shows that government and judges are also self-interested and hence may not have incentives to impose stringent nuclear liability on operators under the tort system (Ramseyer 2011: 19). Nevertheless, the Fukushima accident shows that it remains important to set financial security at a sufficiently high level to cover the total accident costs.

When finally looking at the third aspect of the international conventions that has received substantial criticism, being public funding, again Japan seems to do relatively better than the Chinese regime or the international regime. Under the Paris Convention, a three-tiered compensation system is established. The Installation State needs to make public funds available to cover the second tier of damage and the contracting parties together should provide a collective fund to provide the third tier of compensation. The public funds intervention is even strengthened under the second generation of conventions. There was a shift toward public funding in those conventions (Van den Borre 2007). The required amount of public funds from Installation States under the Paris Convention has increased substantially in the second generation of conventions. The shift toward public funding has been criticized by law and economic literature, since it constitutes a subsidy to

\footnotetext{
${ }^{80}$ For example, unlimited liability was adopted in Austria and Germany. In Denmark and Sweden, the unlimited liability is seriously considered or will be applicable when the revised Paris Convention comes into force. See Schwartz (2009), 43, 54
} 
operators and thus further dilutes the incentives for operators to take efficient care (Faure and Van den Borre 2008: 261, 305). Again, China suffers from the same problem as the international regime since public funds (an indemnity) are provided when the damage is higher than the financial limit of the operator. In Japan, this amount of 120 billion yen ( 0.95 billion Euro) is in principle paid by the operator, either (in the general case) via liability insurance or, in case of uninsurable risks (more particularly damage resulting from earthquakes, tsunamis or volcanoes) via an indemnity agreement with government. But the indemnity agreement is, unlike state aid in the international regime, not a pure subsidy since the operator has to pay a fee for the coverage provided by government via the indemnity agreement. Of course, one could question whether the fee paid by the operator for the indemnity agreement is comparable to commercially risk-dependent premiums that would be charged on a commercial insurance market. One report shows that in 1998, the premium rate was set at an average of 7.9 percent of the total amount of coverage (Watabe 2006: 222), which is substantially higher than the rate of indemnity fee $(0.03 \text { or } 0.015 \%)^{81}$ or even the increased rate of $2 \%$ after the Fukushima Accident. However, it should be born in mind that given the lack of actuarial data for nuclear accidents, commercial premiums are usually set higher than the actuarial premium. Thus, the difference between the rate of indemnity fee and actuarial premium - a more accurate measure of risk-may not be that large.

Another characteristic of Japan is that a risk-sharing pool among nuclear operators was established after the Fukushima accident. Law and economic literature shows that pooling systems can cover catastrophic losses or less predictable risks and at the same time not dilute the precaution incentives (Faure and Van den Borre 2008; Pelzer 2007). A retrospective pooling system exists in both America and Germany, providing a second layer of coverage for nuclear liability (Pelzer 2007). However, the Japanese pooling system was established only after a major accident happened. Hence, it cannot create incentives to the liable party who already caused the damage.

\section{Concluding remarks}

This paper provided a comparative analysis, also using an economic perspective, on the liability for nuclear accidents in the international regime, Japan and China. The comparison is interesting since Japan is an important nuclear power and China probably will be, although neither of them joined the international conventions.

The international conventions have already been criticized for many years from the perspective of economic analysis of law for three main reasons: the exclusive channelling of liability to operators limits the incentives of others who could equally take measures to prevent a nuclear accident; the financial cap on the liability of the operator creates an implicit subsidy, potentially leads to under deterrence and to externalization of harm; this effect is moreover strengthened by providing public funding. Hence, the risk creators do not need to pay a price (Van den Borre 2007; Faure 1995).

The case of Japan and more particularly the recent Fukushima incident in fact reinforce this criticism. Japanese law is interesting in the sense that it has unlimited liability of the operator and generates higher amounts of compensation for which the operator pays than the international regime. Moreover, Japan has different forms of government intervention.

81 Section 3, the Order for the Execution of the Act on Indemnity Agreements for Compensation of Nuclear Damage. 
In one case, an indemnity agreement is concluded between the operator and the government whereby government intervention is not provided for free but the operator pays a fee for the indemnity provided by government.

The Chinese regime, so we indicated, shows many of the inefficiencies of the international regime: a relatively low financial cap, channelling (but it might not be exclusive) and a government indemnity.

In this article, we discussed the different elements of nuclear liability and compensation in three regimes: definition of damage, scope of liability, liable parties and compensation. Of these three regimes, only the international conventions define nuclear damage explicitly. The second generation broadened the scope significantly to include both the more traditional headings (damage to persons and property) and the newer ones (economic losses and environmental damage). The Japanese system does not define the type of damage compensable, but practice shows that the compensable scope can be broad, including also pure economic losses and some cleanup costs. In China, personal causalities, property damage and environmental damage are compensable. However, what constitutes environmental damage needs further clarification. Nuclear accidents can cause harm not only to persons but also serious environmental damage. Hence a broader definition can give the liable parties incentives to internalize the full costs they create.

Strict liability was established in three regimes, which can give the liable parties incentives to take efficient care. However, different defenses are allowed in these regimes. The "natural disaster of an exceptional character" is excluded in the second generation of conventions and in the 2007 Reply in China. Though such a defense is allowed in Japan, the practice shows that the "exceptional character" is explained very narrowly. This is desirable, since it will give the operators incentives to take precautionary measures against natural disasters.

A channelling of liability is adopted in three regimes (though it may not be exclusive in China). Hence, only nuclear operators are liable for nuclear damage. The other parties, which can equally contribute to risks are excluded from the liability risks, hence may not have incentives to take care. The mere fact that the Fukushima incident may have been caused, not only by the operator's wrongful behavior, but probably by a design failure as well again shows the problematic nature of an exclusive channelling of liability to the operator. Contrary to the legal channelling in the discussed three regimes, the design in the US provides another possibility. The US did not join the international conventions but adopted its own Price-Anderson Act in $1957 .{ }^{82}$ The Price-Anderson Act, e.g., has no legal channelling, but American Nuclear Insurers (ANI) provides a so-called omnibus coverage for all parties involved in the nuclear operation as a result of which a so-called economic channelling takes place (Van den Borre 2007: 299-302). Hence, the other parties such as designers or nuclear suppliers are still potentially liable. But the omnibus coverage taken by nuclear operators ensures the available compensation.

As for the compensation, the liability in the international and in the Chinese regimes is capped. Such a cap does not exist in Japan. However, the limited liability under corporate law may still make the operators not exposed to the full risks they create. In a recent provocative paper, Ramseyer argued that earthquakes are so common in Japan that TEPCO decided to build its reactor at the site which is vulnerable to earthquake risks, because it knew it "would not pay the full cost of a melt-down anyway" (Ramseyer 2011: 457). He holds that the nuclear operator is, under the Japanese system, able to externalize liability since liability will reach a de facto cap at the value of its assets. Therefore, requiring

82 Act to amend the Atomic Energy Act of 1954 (Price-Anderson), Pub. L No. 85-256, 71 stad. 576 (1957). 
sufficient financial security from nuclear operators is very important to ensure sufficient compensation and efficient prevention.

Insurance is used broadly in the three regimes. The difference exists with regard to public funding. In both the international and the Chinese regimes, a higher layer of compensation is provided by the government. This consists of a subsidy to the nuclear operators who do not need to pay a price for the coverage. In Japan, the operators are required to pay an indemnity fee for a coverage under an indemnity agreement. A risksharing pool was also established after the Fukushima accident. Such a pool, theoretically speaking, has the advantage to provide mutual monitoring incentives among operators and provides them additional preventive incentives. However, it should be established before the accident instead of after to ensure the incentives.

This comparison between the international, the Japanese and Chinese regimes shows considerable differences and also considerable intensities as far as the regulation is concerned. Although each of the regimes has its own particularities, it can definitely not be said that the international regime is in any way optimal or better than national regimes. This may probably be the case when compared to the Chinese regime, which is mostly due to the fact that that regime has not been fully developed. However, the regime in Japan seems to be better, as far as exposing nuclear operators to the social cost of their activities is concerned, than the international regime or the Chinese. But even if one can consider the regime in Japan the "better" one of the three we have discussed in this article (more particularly because Japan has unlimited liability), the Fukushima incident also showed an important lesson that Japan shares with the international regime, being the exclusive channelling of liability, thus insufficiently exposing others who equally contribute to risk to the accident costs.

Acknowledgments Michael Faure is grateful to the China Ministry of Education and to the Research Centre for Law and Economics of CUPL for their support.

\section{References}

Ameye, E. (2010). Channelling of nuclear third party liability towards the operator: Is it sustainable in a developing nuclear world or is there a need for liability of nuclear architects and engineers? European Energy and Environmental Law Review, 19(1), 33.

Cai, X (2004). The Civil Liability for Nuclear Damage (Ph.D dissertation, Wuhan University, China) (pp. 291-292). http://c79.cnki.net/oldcnki/index4.htm. Accessed 17 February 2014.

Duncan, E. J. Currie. (2008). The problems and gaps in the nuclear liability conventions and an analysis of how an actual claim would be brought under the current existing treaty regime in the event of a nuclear accident. Denver Journal of International Law and Policy, 35(1), 85-127.

Faure, M. (1995). Economic models of compensation for damage caused by nuclear accidents: some lessons for the revision of the Paris and vienna conventions. European Journal of Law and Economics, 2(1), $21-43$.

Faure, M., \& Fiore, K. (2008). The civil liability of european nuclear operators: Which coverage for the new 2004 protocols? Evidence from France. International Environmental Agreements, 8, 228-248.

Faure, M., \& Fiore, K. (2009). An economic analysis of the nuclear liability subsidy. Pace Environmental Law Review, 26, 419-447.

Faure, M., \& Liu, J. (2012). The tsunami of March 2011 and the subsequent nuclear incident at Fukushima: Who compensates the victims? William and Mary Environmental Law and Policy Review, 37, 129-218.

Faure, M., \& Van den Borre, T. (2008). Compensating nuclear damage: A comparative economic analysis of the US and international liability schemes. William and Mary Environmental Law and Policy Review, 33(1), 219-286.

Faure, M., \& Weiqiang, H. (2011). Towards a reform of environmental liability in China: An economic analysis. Asia Pacific Journal of Environmental Law, 13, 225-247. 
Hirokazu, O. (2000). Nuclear damage and liability insurance for nuclear damage. Oita University economic review, 51(6), 21-47.

Japan Nuclear Energy Safety Organization (2010). Current status of nuclear facilities in Japan (p. 1) http:// www.jnes.go.jp/english/activity/unkan/e-unkanhp1/e-unkanhp1-2010/book1/book.pdf. Accessed 17 February 2014.

Jia, Y. (2011). Nuclear liability insurance in China, China Insurance 218, 47 (Chinese).

Liu, J., \& Faure, M. (2012). Compensating nuclear damage in China. Washington University Global Studies Law Review, 11(4), 781-816.

Mosk, M. (2011). Fukushima: Mark 1 nuclear reactor design caused GE scientist to quit in protest, in ABC World News. http://abcnews.go.com/Blotter/fukushima-mark-nuclear-reactor-design-caused-gescientist/ story?id=13141287\#.UEft8Y2PWRE. Accessed 17 February 2014.

Nomura, T., Hokugo, T. \& Takenaka, C. (2012). Japan's nuclear liability system. In OECD Nuclear Energy Agency (Ed.), Japan's compensation system for nuclear damage: As related to the TEPCO Fukushima daiichi nuclear accident (pp. 15-28). https://www.oecd-nea.org/law/fukushima/7089-fukushimacompensation-system-pp.pdf. Accessed 17 February 2014.

OECD (2008). Nuclear legislation in OECD countries, regulatory and institutional framework for nuclear activities: Sweden, 13. http://www.oecd-nea.org/law/legislation/sweden.pdf. Accessed 17 February 2014.

Pelzer, N. (2007). International pooling of operators' funds: An option to increase the amount of financial security to cover nuclear liability? Nuclear Law Bulletin, 79, 37.

Ramseyer, M. J. (2011). Why power companies build nuclear reactors on fault lines: The case of Japan. Theoretical Inquiries in Law, 31(2), 457.

Schäfer, H., \& Müller-Langer, F. (2009). Strict liability versus negligence. In M. Faure (Ed.), Tort law and economics (pp. 3-45). Cheltenham/Northampton: Edward Elgar.

Schwartz, J. A. (2006). International nuclear third party liability law: The response to Chernobyl, In International Nuclear Law in the Post-Chernobyl Period (pp. 41-44), Paris, OECD-NEA.

Schwartz, J. A. (2009). Great expectations: Where do we stand with the international nuclear liability conventions? In Norbert Pelzer (Ed.), European nuclear liability law in a process of change Berlin, Nomos, 43 et seq.

Shavell, S. (1980). Strict liability versus negligence. Journal of Legal Studies, 9, 1-25.

Trebilcock, M., \& Winter, R. A. (1997). The economics of nuclear accident law. International Review of Law and Economics, 17, 215-243.

Van den Borre, T. (2007). Shifts in governance in compensation for environmental damage: 20 Years after Chernobyl. In M. Faure \& A. Verheij (Eds.), Shifts in compensation for environmental damage (pp. 261-311). Vienna: Springer.

Vásquez-Maignan, X. (2010). Nuclear liability in China. Asia Power, 20-22. http://www.gide.com/front/ files/AsianPower_GLN_NuclearLiabilityInChina_feb2010.pdf. Accessed 17 February 2014.

Vásquez-Maignan, X. (2011). Fukushima: Liability and compensation. NEA News, 29(2), 9-11.

Watabe, A. (2006). An economic analysis of nuclear accidents in Japan. In G. Liu (Ed.), Perspectives on international state and local economics (pp. 209-234). New York: Nova Science Publishers Inc.

Weitzdörfer, J. (2011). Die haftung für nuklearschäden nach japanischem atomrecht-rechtsprobleme der reaktorkatastrofe von Fukushima I ((Liability for Nuclear Damages Pursuant to Japanese Atomic Law_Legal Problems Arising from the Fukushima I Nuclear Accident). Zeitschrift für Japanisches Recht, Journal of Japanese Law, 31, 61-115. 